\title{
Konjac glucomannan polysaccharide and inulin oligosaccharide enhance the colonic mucosal barrier function and modulate gut-associated lymphoid tissue immunity in C57BL/6J mice
}

\author{
Chih-Hsuan Changchien ${ }^{1,2}$, Yi-Chun $\mathrm{Han}^{3}$ and Hsiao-Ling Chen ${ }^{4,5 *}$ \\ ${ }^{1}$ Department of Biotechnology, Asia University, Taichung City 413, Taiwan \\ ${ }^{2}$ Department of Plastic Surgery, Chia-Yi Christian Hospital, Chia-Yi City 600, Taiwan \\ ${ }^{3}$ Department of Nutrition, Chung Shan Medical University, Taichung City 402, Taiwan \\ ${ }^{4}$ Department of Food, Nutrition and Health Biotechnology, Asia University, Taichung City 413, Taiwan \\ ${ }^{5}$ Department of Medical Research, China Medical University Hospital, Taichung City 404, Taiwan
}

(Submitted 10 June 2019 - Final revision received 14 October 2019 - Accepted 29 October 2019)

\section{Abstract}

Both konjac glucomannan (KGM) and inulin oligosaccharide have been shown to improve bowel function, but their effects on the mucosal barrier function and immunity are not fully understood. The aim of the present study was to determine the effects of a low-level supplementation of dietary fibres on the colonic mucosal barrier function, antioxidant enzyme defence and immunity. C57BL/6J mice (6 weeks of age, eight per group) were randomly assigned to consume one of the following diets: control or control diet supplemented with $2 \%$ (w/w) of KGM, inulin oligosaccharide (degree polymerisation = 8) or KGM+inulin (1\%, w/w each (K+I)). Fresh faeces were collected on days $19-21$. Mice were killed on day 22 after fasting. Segments of colon tissues were processed for histological procedure and stained for acidic mucins and tight junction protein marker zona occludin-1 (ZO-1). The remaining tissues were processed to determine the gene expression of mucin 2 , tight junction proteins, antioxidant enzymes and cytokines. The plasma cytokines were measured. Results indicated that KGM, inulin and $\mathrm{K}+\mathrm{I}$ significantly increased the mucosal layer thickness, mucin density (granule number/crypt) and gene expression of $M u c 2$ as compared with the control. All fibre treatments increased the gene expressions of ZO-1, occludin, glutathione peroxidase, glutathione $S$-transferase $\pi$, catalase and IL-10. In addition, all fibre treatments increased faecal butyrate and probiotics, and plasma IL-10 concentrations. In conclusion, supplementation of low-level, $2 \%(\mathrm{w} / \mathrm{w})$, of $\mathrm{K}+\mathrm{I}$ was sufficient to enhance the mucosal barrier function and anti-inflammatory status.

Key words: Mucosal barrier: Tight junctions: Immunity: Konjac glucomannan: Inulin

The mucosal barrier is an important defence system that protects the host from pathogenic and immunogenic factors present in the lumen ${ }^{(1)}$. This barrier mainly consists of the mucus layer coating the epithelium, epithelium lining, tight junctions and microbiota $^{(1)}$. In addition to the physical barrier, the mucosa cells have antioxidant defence system that modulates the redox balance ${ }^{(2)}$ and a particular immune system, namely, the gut-associated lymphoid tissue (GALT) ${ }^{(1)}$. Therefore, the intestinal mucosal layer forms a rather important part of the immune system.

Intestinal mucins are large proteins characterised by tandem repeats rich in serine, threonine, and proline, which are highly O-glycosylated ${ }^{(3)}$. The two types of mucins are secretory and membrane associated. The secretory mucins are produced in the goblet cells of the mucosa and secreted into the intestinal lumen to form a gel-like layer. Mucin 2 is an important secretory mucin in the large intestine ${ }^{(4)}$. Deletion of $M u c 2$ gene in mice results in spontaneous tumorigenesis in the colon ${ }^{(5)}$. Previous studies also indicate that alterations of mucin peptide and mucin glycosylation occur during carcinogenesis ${ }^{(6)}$. Therefore, the proper distribution and expression of mucins are important mechanisms for the mucosal defence system.

Tight junctions, also called zonula occludens, form continuous intercellular barrier between the intestinal epithelial cells ${ }^{(7)}$. Tight junctions are required to separate tissue spaces, regulate selective movement of solutes across the epithelium and maintain mucosa barrier function. A leaky epithelium may lead to translocation of endotoxins and

Abbreviations: GALT, gut-associated lymphoid tissue; KGM, Konjac glucomannan; ZO-1, zona occludin-1.

* Corresponding author: Hsiao-Ling Chen, fax +886-4-23321215, email hlchen908@asia.edu.tw 
bacterial antigens and causes a persistent activation of the adaptive immune system in the GALT and systemic immune system $^{(7)}$. Currently many proteins have been identified as components of the tight junction ${ }^{(8)}$. In general, the architecture can be divided into two compartments; one is the transmembrane barrier proteins (occludin, claudins, etc.) and the other is peripheral scaffolding proteins (such as zona occludin-1 (ZO-1), afadin, etc.), which are in turn linked to actin and microtubules $^{(8)}$.

The colonic mucosa is constantly challenged by the reactive oxidative substances (ROS) produced from the microbiota and lumen contents ${ }^{(9)}$. An imbalance in the cellular redox system of mucosa leads to elevated ROS level and subsequently causes gastrointestinal tract inflammation and even colorectal cancer $^{(9,10)}$. Previous studies have indicated that $5 \%$ supplementation of dietary fibres up-regulated certain colonic antioxidant enzyme gene expression against the oxidative stress caused by the high-fat diet ${ }^{(2)}$. However, whether lower level supplementation of fibre could up-regulate the colonic antioxidant defence remains to be examined.

The GALT is composed of Peyer's patch and lymphocytes such as $\mathrm{T}$ and $\mathrm{B}$ cells. The effect of konjac glucomannan (KGM) on the immune response of GALT has not been determined. In addition, most previous studies determined the modulatory effects of synbiotic (inulin and probiotic), instead of inulin oligosaccharide per se, on immunity ${ }^{(11)}$. Therefore, more studies are required to conclude the role of dietary fibres on immunity.

Derived from the tubers of Amorphophallus konjac C. Koch, KGM is composed of $\beta$-1, 4-linked D-glucose and D-mannose units joined together with branches through $\beta$-1,6-glucosyl units $^{(12)}$. The KGM polysaccharide is processed into various vegetarian food products commonly consumed in the Asian countries. Inulin, found in the underground tuber of chicory (Cichorium intybus), is an oligomer or polymer of $\beta$-D-fructose containing two to mostly sixty monomeric units that are linked by $\beta-(2 \rightarrow 1)$ glycosidic bridges ${ }^{(13)}$. The fraction of inulin with the degree of polymerisation lower than 10, namely, inulin oligosaccharide, is widely used as a supplement in functional food. Both KGM and inulin oligosaccharide have been shown to increase the production of SCFA and stimulate the growth of bifidobacteria and lactobacilli in animal/human studies $^{(13-15)}$. However, the effects of these soluble fibres on the mucosal barrier function have not been determined, which need to be determined in animal models, so that the histology of mucosal layer could be clearly observed. In addition, dietary fibres in the human diet are indigestible carbohydrates with a wide range of polymerisation and solubility. Therefore, the fibre treatments in the present study included a polymer (KGM), an oligosaccharide (a fraction of chicory inulin) and their mixture.

The present study was undertaken to investigate the effects of KGM polysaccharide, inulin oligosaccharide and the mixture on the colonic mucosal barrier, mucins, tight junction proteins, antioxidative enzymes, GALT-associated cytokines, faecal SCFA and microbiota. Plasma cytokine levels were also determined to evaluate the systemic immune effects of these dietary fibres. In order to be applicable to humans, the level of fibre supplementation was only $2 \% \mathrm{w} / \mathrm{w}$, which is equivalent to $10 \mathrm{~g} / \mathrm{d}$ of normal human diet.

\section{Material and methods}

\section{Animals}

Male C57BL/6J mice were obtained at 5 weeks of age from the National Laboratory Animal Breeding and Research Center. Every three mice were housed in a solid-bottomed plastic cage with stainless wire bar lid and wood shavings for bedding in an animal holding room maintained on a 12-h light-12-h dark cycle at $23-25^{\circ} \mathrm{C}$ and $50 \%$ humidity. In the present study, all animals were allowed free access to water and food. The care and use of animals followed the Animal Protective $\mathrm{Act}^{(16)}$ and the guidelines of the National Research Council ${ }^{(17)}$. All experimental procedures involving animals were approved by the Institutional Animal Care and Use Committee (IACUC) of Chung Shan Medical University (approved number 1382).

\section{Experimental design}

After 1 week of adaptation, mice ( 6 weeks of age) were randomly assigned to consume one of the following diets (total $n 32, n 8$ per group): control (control group) or fibresupplemented (KGM 2\%, inulin oligosaccharide $2 \%$ and KGM $1 \%+$ inulin oligosaccharide $1 \%$ w/w) diets. Mice were killed after $21 \mathrm{~d}$ of dietary intervention. The control diet was modified from AIN-93 G diet ${ }^{(18)}$, and the compositions of all diets are listed in Table 1. The konjac powder contains (w/w on dry weight basis) $80 \%$ glucomannan, $8 \%$ sugar, $3.4 \%$ protein, $3.8 \%$ lipid and $1.7 \%$ ash; the inulin powder contains (w/w) $85 \%$ fructo-oligosaccharide (mean degree of polymerisation 8 ) and $8 \%$ sugar. The diet was adjusted based on the purity of konjac and inulin powder to provide $5 \%(\mathrm{w} / \mathrm{w})$ dietary fibre. All mice had free access to food and water throughout the study. The signs of health were observed daily. However, no adverse event occurred during the study.

Table 1. Composition of experimental diets

\begin{tabular}{|c|c|c|c|c|}
\hline Group & $\begin{array}{c}\text { Control }^{*} \\
(\mathrm{~g} / \mathrm{kg})\end{array}$ & KGM (g/kg) & $\begin{array}{l}\text { Inulin } \\
(\mathrm{g} / \mathrm{kg})\end{array}$ & $\mathrm{K}+\mathrm{I}(\mathrm{g} / \mathrm{kg})$ \\
\hline Maize starch & 529.5 & 504.5 & $506 \cdot 1$ & $505 \cdot 3$ \\
\hline Casein & $200 \cdot 0$ & $200 \cdot 0$ & $200 \cdot 0$ & $200 \cdot 0$ \\
\hline Sucrose & $100 \cdot 0$ & $100 \cdot 0$ & $100 \cdot 0$ & $100 \cdot 0$ \\
\hline Soyabean oil & $70 \cdot 0$ & $70 \cdot 0$ & $70 \cdot 0$ & $70 \cdot 0$ \\
\hline Cellulose & $50 \cdot 0$ & $50 \cdot 0$ & $50 \cdot 0$ & $50 \cdot 0$ \\
\hline Inulin & - & - & $23 \cdot 4$ & $11 \cdot 7$ \\
\hline Konjac glucomannan & - & $25 \cdot 0$ & - & $12 \cdot 5$ \\
\hline AIN 93G mineral Mix & $35 \cdot 0$ & $35 \cdot 0$ & $35 \cdot 0$ & $35 \cdot 0$ \\
\hline AIN 93 vitamin Mix & $10 \cdot 0$ & $10 \cdot 0$ & $10 \cdot 0$ & $10 \cdot 0$ \\
\hline L-Cystine & 3.0 & $3 \cdot 0$ & $3 \cdot 0$ & 3.0 \\
\hline Choline bitartrate & 2.5 & $2 \cdot 5$ & 2.5 & 2.5 \\
\hline
\end{tabular}

KGM, Konjac glucomannan; K+I, KGM + inulin; AIN, American Institute of Nutrition. * The control diet was modified from AIN-93 G diet ${ }^{(18)}$. 
Food intake and body weight were determined twice a week. The voided faeces were immediately collected during days 19-21. Aliquots from the 3-d faecal composite were stored at $-20^{\circ} \mathrm{C}$ for further analyses of faecal SCFAs and microflora. Mice were anaesthetised with $\mathrm{CO}_{2}$ on day 22 after an 18-h fasting. Blood was collected from the inferior vena cava. The entire distal colon was removed, cut longitudinally, flushed clean with ice-cold sterile saline. Segments $\left(0.5 \mathrm{~cm}^{2}\right)$ of the distal colon were immediately fixed in $10 \%(\mathrm{v} / \mathrm{v})$ buffered formalin and the remaining tissues were frozen for further analysis.

\section{Histological evaluation}

The formalin-fixed colonic tissues were processed with standard histological procedures. Paraffin sections $(4 \mu \mathrm{m})$ were mounted on microscope slices and were dewaxed with xylene and rehydrated through descending alcohol concentration (100-70\%, w/w). Tissue sections were stained with haematoxylin and eosin. The histology of mucosal layer was observed under a $100 \times$ magnification with a Zeiss Axioskop 2 microscope (Carl Zeiss) equipped with a cooled charge-coupled device (CCD) video camera (Optronics Inc.). The mucosal layer thickness was determined using Lucia Measurement Image Analysis Systems (version 4.81; Laboratory Imaging) using a stage micrometer (Nikon) as a reference.

\section{Mucin density}

The Alcian blue is used to identify the sulphated and carboxylated acid mucopolysaccharides ${ }^{(19)}$. The dewaxed and rehydrated slides were incubated in glacial acetic acid solution $(3 \%, \mathrm{w} / \mathrm{w})$ for $3 \mathrm{~min}, 1 \%(\mathrm{w} / \mathrm{v})$ Alcian blue $(\mathrm{pH} 2 \cdot 5$, in $3 \%$, $\mathrm{w} / \mathrm{w}$ glacial acetic acid) for $30 \mathrm{~min}$ and then $0.5 \%(\mathrm{w} / \mathrm{v})$ eosin solution for $1 \mathrm{~min}$ at room temperature. The mucin granules were enumerated in blind under $100 \times$ magnification and expressed as mucin density (number of mucin granules in each crypt).

\section{Fluorescent in situ immunohistology of tight junction marker protein zona occludin-1}

ZO-1 was determined using the fluorescent in situ immunohistological technique. Paraffin sections $(4 \mu \mathrm{m})$ were dewaxed and rehydrated. Endogenous peroxidase activity of tissue slides were removed by treatment with $3 \%(\mathrm{w} / \mathrm{w})$ hydrogen peroxide for $20 \mathrm{~min}$. Tissue slices were then blocked with $5 \%(\mathrm{w} / \mathrm{w})$ goat serum in $0 \cdot 1 \mathrm{~m}$ PBS containing $0 \cdot 1 \%(\mathrm{w} / \mathrm{v})$ tween-20 for $1 \mathrm{~h}$. The ZO-1 was detected with a rabbit antiZO-1 polyclone antibody (Abcam Co.) at a dilution of 1:50 at $37^{\circ} \mathrm{C}$ for $1 \mathrm{~h}$, followed by a Alexa Fluor $^{\circledR}{ }^{-}$-conjugated goat anti-rabbit IgG polyclone antibody (Abcam Co.) at a dilution of $1: 10$ at $37^{\circ} \mathrm{C}$ for $1 \mathrm{~h}$. Slides were mounted with fluoroshield mounting medium containing 4',6-diamidino-2-phenylindole (DAPI) (Abcam Co.). Fluorescence was observed and determined at 200× magnification with a Zeiss Axioskop 2 microscope (Carl Zeiss) fitted for epifluorescence device and a cooled CCD video camera (Optronics Inc.). The density of
ZO-1 was determined as the red area (ZO-1 positive) over the blue area (nuclei stained by DAPI) and further calculated relative to that of the control group with Lucia Measurement Image Analysis Systems (Laboratory Imaging).

\section{Relative gene expression}

The gene expressions of $M u c 2$, tight junction proteins including ZO-1 and occludin, antioxidant enzymes including glutathione peroxidase 2 ( GPX2), glutathione $S$-transferase $\pi$ (GST), catalase (CAT) and superoxide dismutase 1 (SOD1) and cytokines such as $T N F-\alpha$ and $I L-1 O$ were determined using quantitative real-time PCR (qRT-PCR). The RNA were isolated according to the method described previously ${ }^{(2)}$. Briefly, the distal colon $(50 \mathrm{mg}$ ) were homogenised in $1 \mathrm{ml} \mathrm{REzol}^{\mathrm{TM}} \mathrm{C} \& \mathrm{~T}$ reagent (Protech Technology). After addition with $0.2 \mathrm{ml}$ chloroform, the samples were vigorously mixed and then centrifuged at $12000 \boldsymbol{g}$ for $15 \mathrm{~min}$ at $4^{\circ} \mathrm{C}$. The supernatant was mixed with an equal volume of isopropanol (J. T. Baker) and centrifuged at $12000 \mathrm{~g}$ for $10 \mathrm{~min}$ at $4^{\circ} \mathrm{C}$ to obtain the RNA pellets. After washing the pellets with $75 \%$ ethanol, the RNA was dissolved in RNAase-free ultrapure water and stored at $-70^{\circ} \mathrm{C}$ until further analysis. The concentration and quality of RNAs were determined at 260/280 $\mathrm{nm}$ absorbance.

The complementary DNAs were synthesised using random primers (Applied Biosystems Life Technologies) in a thermal cycler (TaKaRa Biomedical) at $25^{\circ} \mathrm{C}$ for $10 \mathrm{~min}, 37^{\circ} \mathrm{C}$ for $2 \mathrm{~h}$ and $85^{\circ} \mathrm{C}$ for $5 \mathrm{~min}$. The qRT-PCR was performed using TaqMan gene expression assays (Applied Biosystems Life Technologies) with the StepOne Real-Time PCR system (Applied Biosystems Life Technologies). The exact primer and probe sequences were not provided due to the proprietary issue and policy of the supplier. The TaqMan primer/probe identification numbers of genes are provided in the supplementary material. The qRT-PCR was performed at $50^{\circ} \mathrm{C}$ for $2 \mathrm{~min}, 95^{\circ} \mathrm{C}$ for $10 \mathrm{~min}$ and fifty cycles at $95^{\circ} \mathrm{C}$ for $15 \mathrm{~s}$ and $60^{\circ} \mathrm{C}$ for $1 \mathrm{~min}$. The relative gene expression of each target gene was first normalised to that of $\beta$-actin and further calculated relative to that of the control group using the comparative threshold cycle $\left(\mathrm{C}_{\mathrm{t}}\right)$ method. The fold difference in gene expression was calculated as $2^{-\Delta \Delta C t(2)}$.

\section{Plasma cytokines}

The plasma TNF- $\alpha$ and IL-10 were determined using ELISA kits (eBioscience), according to the manufacturer's instructions.

\section{Faecal SCFA}

Aliquots $(0.5 \mathrm{~g})$ of faecal composites were analysed for acetate, propionate and $n$-butyrate with 4 -methyl- $n$ valeric acid as an internal standard by the method described previously ${ }^{(14)}$. The SCFA extracted using ether from faecal samples were injected onto a GC (GC-2014; Shimadzu) fitted with a glass capillary column (0.25 mm, $30 \mathrm{~m}$ Stabilwax-DA; Restek Corp.) and a flame ionisation detector. The initial temperature of the oven was $100^{\circ}$ $\mathrm{C}$ and this was raised to $200^{\circ} \mathrm{C}$ at $6^{\circ} \mathrm{C} / \mathrm{min}$. The temperature of the injection port and detector was 210 and $250^{\circ} \mathrm{C}$, respectively. The flow rate of carrier gas, $\mathrm{N}_{2}$, was adjusted to be $1 \mathrm{ml} / \mathrm{min}$. 
Peak areas were analysed with Shimadzu GC solution data analysis program (Shimadzu Corp.).

\section{Quantification of faecal bacteria}

Faecal bifidobacteria, lactobacilli and Clostridia were quantified by the fluorescent in situ hybridisation method as described previously ${ }^{(20-22)}$. In brief, genotypic probes targeting $16 \mathrm{~S}$ rRNA of bacteria were manufactured and tagged with fluorescent markers, which allowed faecal bacterial populations to be quantified with a fluorescence microscope. The probes used were Bif164 (5'-CAT CCG GCA TTACCA CCC-3'), Laal (5'-CAT CCA GTG CAA ACC TAA GAG-3') and Ib1 (5'-GAT GGA ACT GTA ACA AAA CT-3'), specific for bifidobacteria $^{(22)}$, lactobacilli ${ }^{(22)}$ and Clostridia $^{(21)}$, respectively. Aliquots $(5 \mu \mathrm{l})$ of faecal bacterial samples were fixed on the wells of microscopic slides and hybridised with probes (final concentration $25 \mathrm{nmol} / \mathrm{l}$ ) at $50^{\circ} \mathrm{C}$ for $16 \mathrm{~h}$ in humid chambers. After rinsing in washing buffer $(20 \mathrm{mmol} / \mathrm{l}$ Tris- $\mathrm{HCl}, 0.9 \mathrm{~mol} / 1 \mathrm{NaCl}, \mathrm{pH} 7.2$ ) at $50^{\circ} \mathrm{C}$ for $30 \mathrm{~min}$, the slides were air-dried in a dark room. To quantify the total faecal bacteria, the slides were incubated with a nucleic acid stain DAPI $(1.4 \mathrm{mmol} / \mathrm{l})$ for $10 \mathrm{~min}$, followed by washing with washing buffer at $50^{\circ} \mathrm{C}$ for $10 \mathrm{~min}$ and air-dried. Probe fluorescence was observed and determined under the microscopic system as described previously in the present study. The microbial counts are expressed as $\log _{10}$ counts/g faeces.

\section{Statistical analysis}

Data are presented as means and standard deviations and analysed using SPSS (version 12.0; SPSS Inc.). The diet effects were determined using one-way ANOVA followed by post hoc analysis using Tukey's honestly significant difference test. A $P$ value $<0.05$ was considered to be statistically significant.

\section{Results}

Mice were healthy throughout the experiment. The initial body weight for the control, KGM, inulin and $\mathrm{K}+\mathrm{I}$ group was $20 \cdot 45$ (sD 0.54), 20.45 (sD 1.41), 20.46 (sD 1.38) and 20.48 (sD 1.24) g, respectively. The total weight gain during the experiment for the control, KGM, inulin and $\mathrm{K}+\mathrm{I}$ group was 3.80 (sD 0.21), 3.55 (sD 0.23), 3.21 (sD 0.25) and 3.15 (sD 0.35) g, respectively. The weight gain was similar among groups.

Histology of the distal colon indicated that the mucosal layer was intact in all groups (Fig. 1(A)). KGM, inulin and $\mathrm{K}+\mathrm{I}$ significantly increased the mucosal layer thickness by approximately $50 \%$ of the level in the control group $(P<0.05$, respectively) (Fig. 1(B)).

The Alcian blue-positive granules that represented the acidic mucin is shown in Fig. 2(A). KGM, inulin and $\mathrm{K}+\mathrm{I}$ significantly increased the mucin density (granule number/crypt) by $77 \cdot 8$ (sD 7.8)\% $(P<0.01), 55.6($ SD 8.8$) \%(P<0.01)$ and 77.8 (sD $10 \cdot 0) \%(P<0 \cdot 01)$, respectively, compared with the level in the control group (Fig. 2(B)). In addition, KGM, I and $\mathrm{K}+\mathrm{I}$ increased Muc2 gene expression by 0.37 (SD 0.04)-fold $(P<0.05), 0.30$ (sD 0.07)-fold $(P<0.05)$ and 0.34 (sD 0.05)-fold $(P<0.05)$, respectively (Fig. $2(\mathrm{C})$ ).

We determined the tight junction protein using both the qRT-PCR (Fig. 3(A)) and fluorescent in situ immunohistological staining (Fig. 3(B)). The qRT-PCR results indicated that KGM, $\mathrm{I}$ and $\mathrm{K}+\mathrm{I}$ increased $Z O-1$ gene expression by 0.49 (sD 0.05)-fold $(P<0.05), 0.35$ (sD 0.04)-fold $(P<0.05)$ and 0.42 (sD 0.06)-fold $(P<0.05)$, respectively (Fig. 3(A)). KGM, $\mathrm{I}$ and $\mathrm{K}+\mathrm{I}$ increased occludin gene expression by 0.37 (sD 0.04)-fold $(P<0.05), 0.30$ (sD 0.07)-fold $(P<0.05)$ and 0.34 (sD 0.05)-fold $(P<0.05)$, respectively. The fluorescent in situ immunohistological staining only applied to ZO-1 since the dietary effect was greater in ZO-1 than in occludin. Result indicated that KGM, I and $\mathrm{K}+\mathrm{I}$ group increased the density of ZO-1

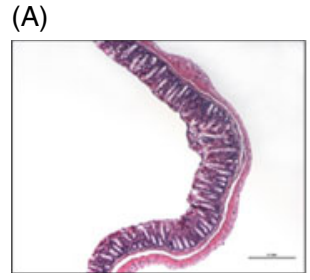

Vehicle

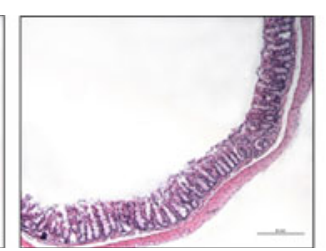

KGM

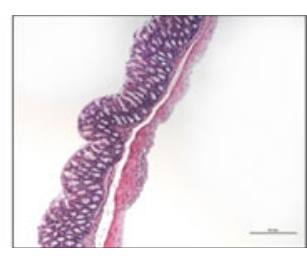

Inulin

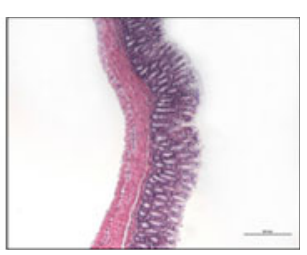

$\mathrm{K}+\mathrm{I}$

(B)

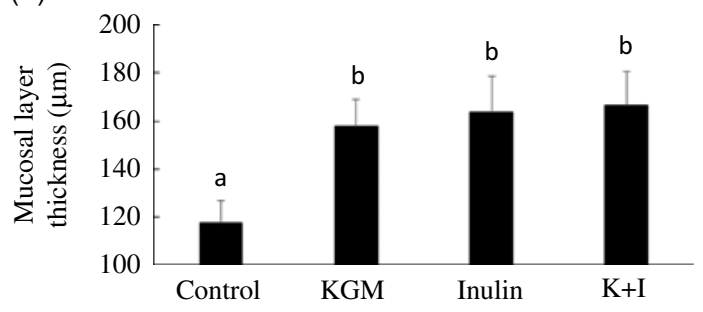

Fig. 1. (Colour online) (A) Histology and (B) mucosal lining thickness of the distal colon. Mice were treated with control diet (control group) or diet supplemented with $2 \%(\mathrm{w} / \mathrm{w})$ fibre derived from Konjac glucomannan (KGM group), inulin oligosaccharide (inulin group) or equal parts (1\%, w/w each) of KGM and inulin $\left(\mathrm{K}+\mathrm{I}\right.$ group) for 3 weeks. Segments $\left(0.5 \mathrm{~cm}^{2}\right)$ of the distal colon were fixed in buffered formalin, processed for histological routine and stained with haematoxylin and eosin. Scale bar represents $200 \mu \mathrm{m}$ under $100 \times$ magnification. Bars are presented as means and standard deviations ( $n 8$ per group). ${ }^{\mathrm{a}, \mathrm{b}} \mathrm{Mean}$ values with unlike letters are significantly different across groups as analysed by one-way ANOVA followed by Tukey's honestly significant difference test $(P<0.05)$. 


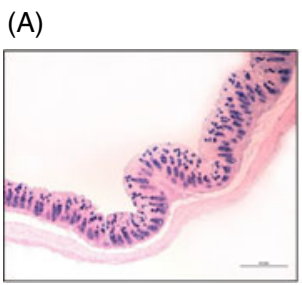

Vehicle

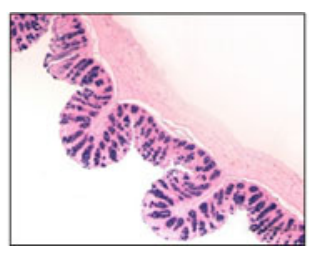

KGM

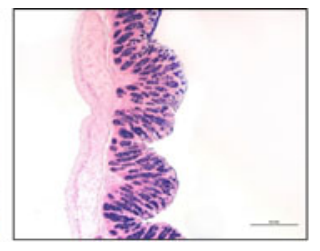

Inulin

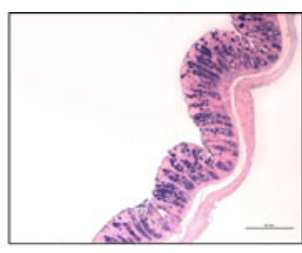

$\mathrm{K}+\mathrm{I}$
(B)

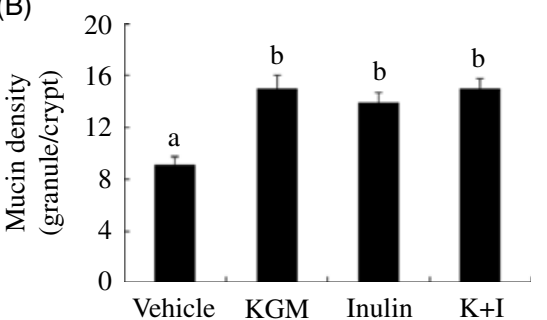

(C)

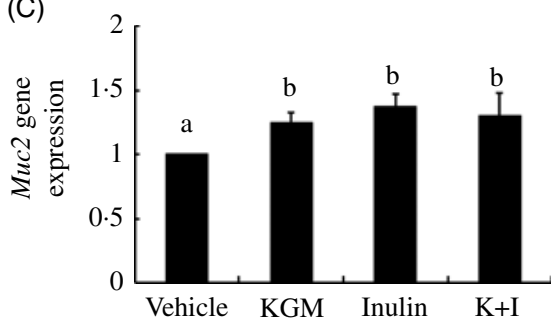

Fig. 2. (Colour online) (A) Alcian blue staining for acidic mucins, (B) mucin density (granule number/crypt) and (C) Muc2 gene expression in the distal colon. Bars are presented as means and standard deviations ( $n 8$ per group). Relative gene expression was normalised using internal control gene $\beta$-actin and compared with that of the control group according to the $2^{-\Delta \Delta C t}$ method. a,b Mean values with unlike letters are significantly different across groups as analysed by one-way ANOVA followed by Tukey's honestly significant difference test $(P<0.05)$. KGM, Konjac glucomannan; K+I, KGM + inulin.

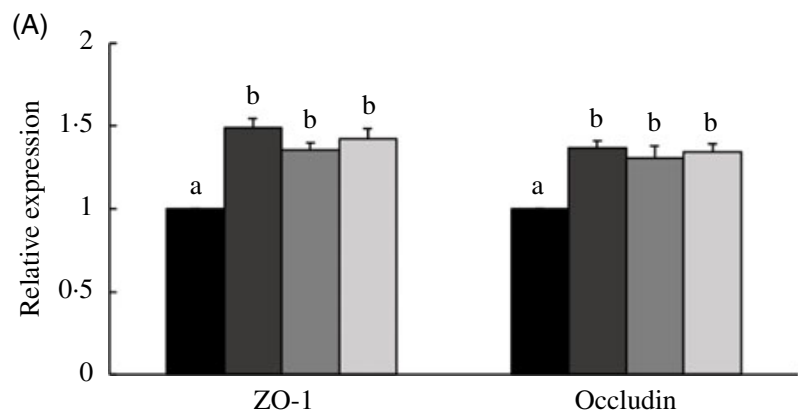

(B)

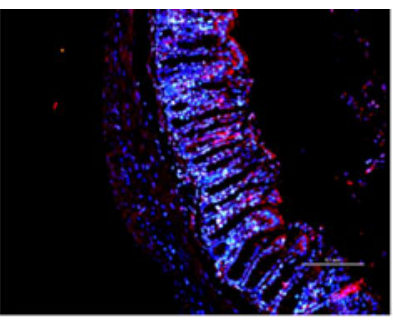

Vehicle

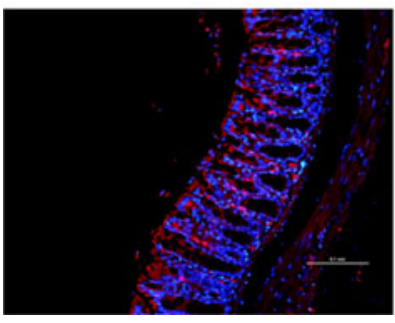

KGM

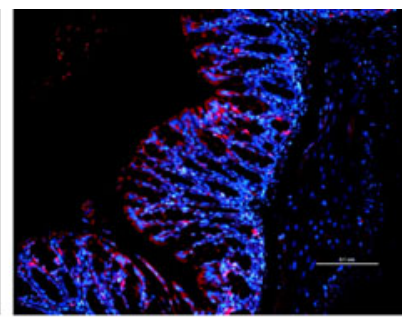

Inulin

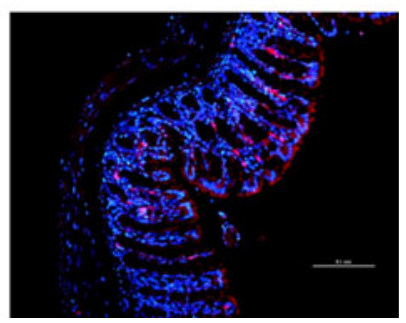

$\mathrm{K}+\mathrm{I}$

Fig. 3. (A) Gene expression of tight junction proteins in the distal colon and (B) fluorescent in situ immunohistology of zona occludin-1 (ZO-1). Relative gene expression was normalised using internal control gene $\beta$-actin and compared with that of the control group according to the $2^{-\Delta \Delta C t}$ method. In the distal colon section, red fluorescence indicates ZO-1 and the blue fluorescence indicates cell nuclei stained with 4',6-diamidino-2-phenylindole (DAPI). Scale bar represents $100 \mu \mathrm{m}$ under $200 \times$ magnification. Bars are presented as means and standard deviations ( $n 8$ per group). a,b Mean values with unlike letters are significantly different across groups as analysed by one-way ANOVA followed by Tukey's honestly significant difference test $(P<0.05)$. (A) $\square$, Control; $\square$, Konjac glucomannan (KGM); $\square$, inulin; $\square, \mathrm{KGM}+$ inulin $(\mathrm{K}+\mathrm{I})$. 
(red area/blue area) by approximately $62 \cdot 2(\mathrm{SD} 5 \cdot 0) \%(P<0.01)$, 22.0 (sD 1.4$) \%(P<0.05)$ and $37.8($ sD 2.2$) \%(P<0.05)$, respectively, compared with the level in the control group.

Dietary fibre treatments increased the antioxidant defence of the colon by up-regulating gene expressions of GPX, GST and CAT (Fig. 4). KGM, inulin and $\mathrm{K}+\mathrm{I}$ significantly increased GPX gene expression by 0.77 (sD 0.21$)$-fold $(P<0.01), 1.17$ (sD 0.17)-fold $(P<0.001)$ and $1.10($ sD 0.08$)$-fold $(P<0.001)$,

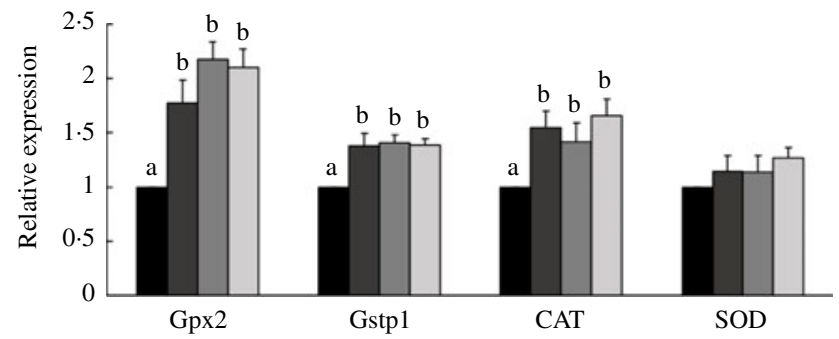

Fig. 4. Relative gene expressions of glutathione S-transferase (GST), glutathione peroxidase (GPX), catalase (CAT) and superoxide dismutase (SOD) in the distal colon. Relative gene expression was normalised using internal control gene $\beta$-actin and compared with that of the control group according to the $2^{-\Delta \Delta C t}$ method. Bars are presented as means and standard deviations ( $n 8$ per group). ${ }^{a, b}$ Mean values with unlike letters are significantly different across dietary groups as analysed by one-way ANOVA followed by Tukey's honestly significant difference test $(P<0.05)$. $\square$, Control; $\square$, Konjac glucomannan (KGM); $\square$, inulin; $\square, \mathrm{KGM}+$ inulin.

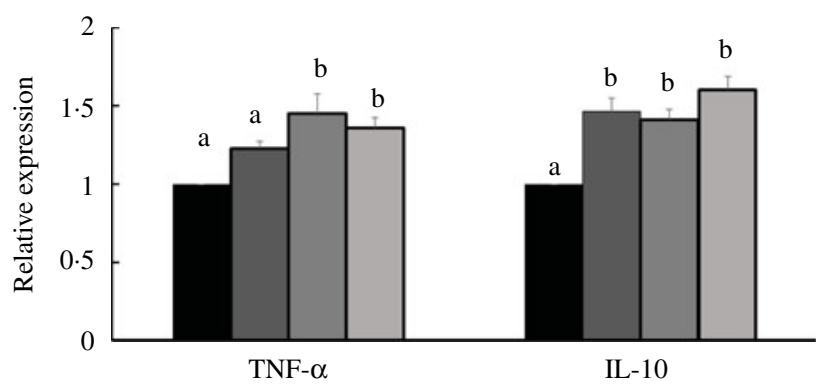

Fig. 5. Relative gene expressions of TNF- $\alpha$ and IL-10 in the colon. Relative gene expression was normalised using internal control gene $\beta$-actin and compared with that of the control group according to the $2^{-\Delta \Delta C t}$ method. Bars are presented as means and standard deviations ( $n 8$ per group). ${ }^{a, b}$ Mean values with unlike letters are significantly different across dietary groups as analysed by one-way ANOVA followed by Tukey's honestly significant difference test $(P<0.05)$. Control; $\square$, Konjac glucomannan (KGM); $\square$, inulin; $\square, \mathrm{KGM}+$ inulin. respectively. KGM, inulin and $\mathrm{K}+\mathrm{I}$ similarly increased GST gene expression by approximately $0 \cdot 4$-fold $(P<0.05)$. KGM, I and $\mathrm{K}+\mathrm{I}$ increased $C A T$ gene expression by 0.54 (SD 0.15 )-fold $(P<0.05), 0.41$ (sD 0.17)-fold $(P<0.05)$ and 0.65 (sD 0.14 )-fold $(P<0 \cdot 05)$, respectively. SOD gene expression was not significantly modulated by any fibre treatment examined in the present study.

Effects of fibres on the colonic cytokine gene expressions are shown in Fig. 5. Inulin and $\mathrm{K}+\mathrm{I}$ increased the relative TNF- $\alpha$ gene expression by 0.45 (sD 0.12)-fold and 0.36 (sD 0.07)-fold, respectively $(P<0 \cdot 05$, respectively). KGM, inulin oligosaccharide and $\mathrm{K}+\mathrm{I}$ increased the relative $I L-10$ gene expression by 0.47 (sD 0.01)-fold, 0.41 (sD 0.07)-fold and 0.6 (sD 0.09)-fold, respectively $(P<0.05$, respectively).

$\mathrm{KGM}$, inulin oligosaccharide and $\mathrm{K}+\mathrm{I}$ increased the plasma IL-10 concentration by approximately $20 \%$ of the level in the control group and did not significantly modulate the plasma TNF- $\alpha$ level (Fig. 6).

Effects of fibres on the faecal SCFA concentrations are shown in Table 2. KGM, inulin oligosaccharide and $\mathrm{K}+\mathrm{I}$ increased the faecal acetate concentration by approximately $60.4 \%$ $(P<0.01), 55.0 \%(P<0.01)$ and $58.9 \%(P<0.01)$, respectively, compared with the level in the control group. KGM, inulin oligosaccharide and $\mathrm{K}+\mathrm{I}$ increased the faecal propionate concentration by approximately $17.0 \%(P<0.05), \quad 33.3 \%$ $(P<0.01)$ and $25.2 \%(P<0.01)$, respectively. KGM, inulin oligosaccharide and $\mathrm{K}+\mathrm{I}$ increased the faecal butyrate concentration by approximately $90.0 \%(P<0.001), 65.0 \%(P<0.01)$ and $80.0 \%(P<0.005)$, respectively. KGM, inulin oligosaccharide and $\mathrm{K}+\mathrm{I}$ increased the faecal total SCFA concentration by approximately $65.7 \%(P<0.01), 52.9 \%(P<0.01)$ and $55.8 \%$ $(P<0 \cdot 01)$, respectively.

After 3 weeks of dietary fibre treatments, the faecal bifidobacteria concentration ( $\log _{10}$ counts/g faeces) in KGM, inulin oligosaccharide and $\mathrm{K}+\mathrm{I}$ group was 11.29 (SD 0.02) $(P<0.001), 11.48$ (sD 0.02) $(P<0.001)$ and 11.40 (sD 0.02$)$ $(P<0.001)$, respectively, greater than that in the control (10.57 (sD 0.02)). KGM, inulin and $\mathrm{K}+\mathrm{I}$ also increased the faecal lactobacilli $\left(\log _{10}\right.$ counts/g faeces) to 11.48 (SD $0 \cdot 02$ ) $(P<0.05), 11.39$ (sD 0.02) $(P<0.05)$ and 11.41 (sD 0.02$)$ $(P<0.05)$, respectively, greater than that in the control $(10 \cdot 86$ (sD 0.03)). However, none of the dietary fibre examined in the present study significantly modulated the faecal Clostridia concentration.
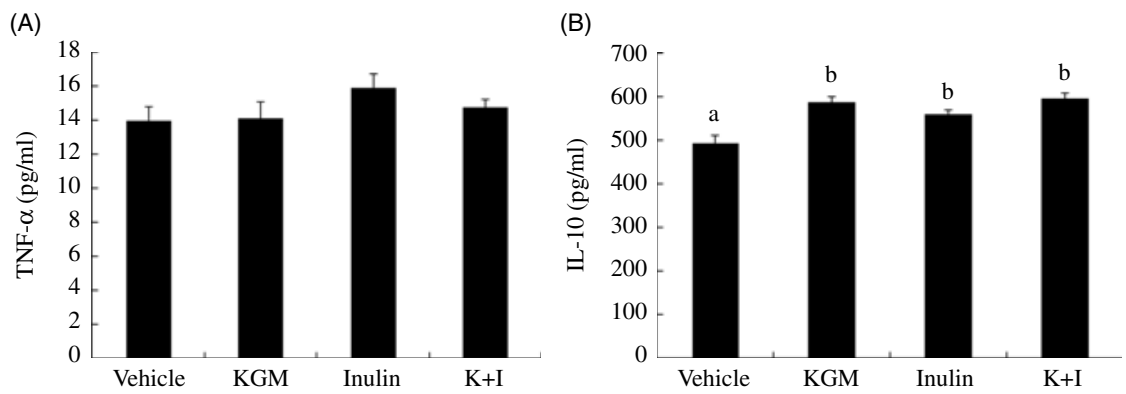

Fig. 6. Plasma TNF- $\alpha$ and IL-10 concentrations. Bars are presented as means and standard deviations ( $n 8$ per group). ${ }^{\text {,bb }}$ Mean values with unlike letters are significantly different across dietary groups as analysed by one-way ANOVA followed by Tukey's honestly significant difference $(P<0.05)$. KGM, Konjac glucomannan; K+I, KGM + inulin. 
Table 2. Effects of different diets on faecal SCFA concentrations $(n 8)$ (Mean values and standard deviations)

\begin{tabular}{|c|c|c|c|c|c|c|c|c|}
\hline & \multicolumn{2}{|c|}{$\begin{array}{c}\text { Control } \\
\text { ( } \mu \mathrm{mol} / \mathrm{g} \text { faeces })\end{array}$} & \multicolumn{2}{|c|}{$\begin{array}{c}\text { Konjac } \\
\text { glucomannan } \\
(\mu \mathrm{mol} / \mathrm{g} \text { faeces })\end{array}$} & \multicolumn{2}{|c|}{$\begin{array}{c}\text { Inulin } \\
(\mu \mathrm{mol} / \mathrm{g} \text { faeces })\end{array}$} & \multicolumn{2}{|c|}{$\mathrm{K}+\mathrm{I}(\mu \mathrm{mol} / \mathrm{g}$ faeces $)$} \\
\hline & Mean & SD & Mean & SD & Mean & SD & Mean & SD \\
\hline Acetate & $70 \cdot 3^{a}$ & 1.3 & $112 \cdot 8^{b}$ & 1.5 & $109 \cdot 0^{b}$ & 1.4 & $111 \cdot 7^{\mathrm{b}}$ & $2 \cdot 3$ \\
\hline Propionate & $12 \cdot 3^{\mathrm{a}}$ & 0.5 & $14 \cdot 4^{\mathrm{b}}$ & 0.4 & $16 \cdot 4^{\mathrm{b}}$ & 0.4 & $15 \cdot 4^{\mathrm{b}}$ & 0.3 \\
\hline Butyrate & $4.0^{\mathrm{a}}$ & 0.1 & $7 \cdot 6^{b}$ & 0.2 & $6 \cdot 6^{\mathrm{b}}$ & 0.1 & $7 \cdot 2^{b}$ & 0.2 \\
\hline Total & $86 \cdot 9^{a}$ & 1.1 & $136 \cdot 0^{\mathrm{b}}$ & 1.3 & $132 \cdot 9^{b}$ & 1.5 & $135 \cdot 4^{b}$ & $2 \cdot 4$ \\
\hline
\end{tabular}

$\mathrm{K}+\mathrm{l}$, Konjac glucomannan + inulin

a,b Mean values with unlike superscript letters within a row are significantly different $(P<0.05$; ANOVA followed by Tukey's honestly significant difference test).

\section{Discussion}

Intestinal mucosal barrier is the largest immune system in the body and plays an essential role to protect the body from potential pathogens. As far as we know, this is the first study to determine the effects of KGM polysaccharide on the intestinal mucosal function and compare the effects of KGM polysaccharide on prebiotic inulin oligosaccharide and the mixture of KGM and inulin oligosaccharide.

Colonic mucosal thickness is an important indicator reflecting the structure and function of the colon mucosa ${ }^{(23)}$. Normal thickness of the colon mucosa represents sufficient quantity and fine morphology of the intestinal epithelium ${ }^{(24)}$. In contrast, colonic mucosa atrophy may cause bacterial translocation ${ }^{(24)}$. However, the effects of soluble fibres on the colonic mucosal thickness are rarely studied. The present study indicated that KGM polysaccharide, inulin oligosaccharide and $\mathrm{K}+\mathrm{I}$ similarly increased the mucosal layer thickness, suggesting the protective roles of these fibres in the mucosal barrier function of the distal colon. Butyrate, which is the major fuel for colonocytes and stimulates colonocyte differentiation and normal proliferation $^{(25,26)}$, could play an important role. The present study and previous studies ${ }^{(2,14,27)}$ did indicate that KGM and inulin oligosaccharide significantly increased the faecal butyrate concentration, which could in turn increase the mucosal layer thickness.

Mucins play protective roles for the mucosal lining. However, the roles of KGM and inulin oligosaccharide in the colonic mucin production have not been determined. In the present study, we suggested that KGM polysaccharide, inulin oligosaccharide and $\mathrm{K}+\mathrm{I}$ similarly enhanced mucosal barrier function by the increased acidic mucin abundance and $\mathrm{Muc2}$ (a secretory mucin) gene expression. Previous studies have shown that orally delivered probiotics may exert their anti-infective effects by influencing the gene expression and composition of mucins and the release of mucus ${ }^{(28)}$. The in vitro co-culture of probiotics (Lactobacillus GG and Lactobacillus plantarum 299v) with colonic epithelial cells (HT-29) enhanced the expression of mucin genes $(M u c 2 \text { and } M u c 3)^{(29)}$. Therefore, the prebiotic effects of fibres examined in the present study may contribute to the enhanced mucin levels in the mucosal barrier. In addition, butyrate is also shown to up-regulate the colonic expression of Muc1-4 in mice ${ }^{(30)}$, which also explains the enhancing effects of KGM, inulin oligosaccharide and $\mathrm{K}+\mathrm{I}$ on the $M u c 2$ gene expression.

Differentiated epithelial cells show apico-basal polarity and contain apical tight junctions. In the present study, we suggested that supplementation of KGM polysaccharide, inulin oligosaccharide and $\mathrm{K}+\mathrm{I}$ promoted the gene expressions of both the peripheral scaffolding protein $\mathrm{ZO}-1$ and the transmembrane barrier protein occludin. Previous in vitro studies have suggested that butyrate increases the transcription of tight junction proteins and induces $\mathrm{ZO}-1$ and occludin redistributions in the cellular membrane ${ }^{(31,32)}$. Therefore, we suggested that the fermentation product, butyrate, of KGM and inulin oligosaccharide by the microbiota was likely to mediate the positive effects of these fibres on tight junction protein expressions.

Previous studies indicated that $5 \%(\mathrm{w} / \mathrm{w})$ of dietary KGM up-regulated the antioxidant defence in the colon by enhancing the gene expression of GPX and CAT ${ }^{(2,27)}$. However, the effect of low-level supplementation of dietary fibres on the intestinal redox system has never been documented. The present study indicated that addition of $2 \%(\mathrm{w} / \mathrm{w}) \mathrm{KGM}$ into the standard diet was enough to up-regulate the colonic antioxidant defence. In addition, the modulatory effects of inulin oligosaccharide and $\mathrm{K}+\mathrm{I}$ were similar to that of KGM. Therefore, regardless of the polymerisation of fibre sources, every dietary fibre examined in the present study enhanced the antioxidant defence system in the colon.

The mucosal barrier contains microbiota that could modulate the innate and adaptive immunity of $\operatorname{GALT}^{(33,34)}$. For example, lipoteichoic acid, a cell wall component of gram-positive bacteria (such as lactobacilli and bifidobacteria), stimulates the innate immunity by increasing the TNF- $\alpha$ secretion from macrophage, which in turn enhances the secretion of NO to kill pathogen/virus ${ }^{(34-36)}$. Therefore, we suggested that the prebiotic of inulin oligosaccharide and $\mathrm{K}+\mathrm{I}$ caused up-regulation of colonic TNF- $\alpha$ gene expression, which could enhance the innate immunity of the GALT. The dietary fibres examined in the present study also modulated the pro- (TNF- $\alpha$ ) and antiinflammation (IL-10) cytokines which mediate the adaptive immunity in GALT $^{(36,37)}$. KGM up-regulated the gene expression of IL-10, but not TNF- $\alpha$, suggesting that KGM induced the anti-inflammatory adaptive immunity. Inulin oligosaccharide equally enhanced the gene expressions of TNF- $\alpha$ and IL-10, 
suggesting that this fibre promoted the GALT immunity to a balanced status. $\mathrm{K}+\mathrm{I}$ increased the gene expression of IL-10 more than that of TNF- $\alpha$, suggesting that $\mathrm{K}+\mathrm{I}$ induced the GALT immunity towards anti-inflammation. Therefore, we suggested that all dietary fibres determined in the present study enhanced the GALT-associated immunity. Furthermore, KGM and K+I modulated the immunity towards anti-inflammatory immunity.

Previous studies have suggested that SCFA mediated the stimulatory effect of inulin on IL-10 production in the Peyer's patch (part of GALT) in rats with colon cancer ${ }^{(38,39)}$. Certain probiotics also have been shown to increase IL-10 production, which results in decreases in allergy, inflammatory bowel disease, autoimmune diseases and inflammatory responses ${ }^{(40)}$. Therefore, the present results suggested that both the SCFA and probiotics may mediate the modulatory effects of the fibre treatments on immunity and possibly help to protect the colon from excessive inflammation.

Dietary fibres are fermented only in the colon, but recent studies have shown that fermentable dietary fibres can modulate systemic inflammatory markers in mice ${ }^{(41)}$ and in men ${ }^{(42)}$. For example, addition of $2.5 \%(\mathrm{w} / \mathrm{w})$ of fructo-oligosaccharide into a standard chow diet reduces the plasma TNF- $\alpha$ and lung IL- $1 \beta$ levels in $\mathrm{D}$-galactose-treated ageing mouse model ${ }^{(41)}$. Daily supplementation of $10 \mathrm{~g}$ dietary fibre (mostly fermentable) reduced the blood inflammatory markers, such as TNF- $\alpha$ and C-reactive peptide, in haemodialysis patients ${ }^{(42)}$. In accordance with these studies, the present result suggested that $2 \%(\mathrm{w} / \mathrm{w})$ of fibre treatment examined in the present study beneficially increased the plasma IL-10 level and modulated the systemic inflammatory status.

In conclusion, the present study suggests that $2 \%(\mathrm{w} / \mathrm{w})$ of KGM polysaccharide, inulin oligosaccharide and the fibre mixture beneficially protect the mucosal barrier function, modulate GLAT-associated immunity and enhance the plasma antiinflammatory cytokine level in mice. Results of the present finding may translate into humans.

\section{Acknowledgements}

The technical support from Yu-Fong Lin for the fluorescent in situ immunohistological staining is appreciated.

The present study was supported by MOST 103-2320-B-468005-MY3 from Ministry of Science and Technology and Chia-Yi Christian Hospital, Taiwan.

H.-L. C. designed, carried out the study and conducted partial data analysis and wrote the manuscript. C.-H. C. participated in the experiment design and co-wrote the manuscript. Y.-C. H. conducted the animal experiment and partial data analysis. All authors read and approved the findings of the study.

There are no conflicts of interest.

\section{Supplementary material}

For supplementary material referred to in this article, please visit https://doi.org/10.1017/S000711451900285X

\section{References}

1. Aureli P, Capurso L, Castellazzi AM, et al. (2011) Probiotics and health: an evidence-based review. Pharmacol Res 63, 366-376.

2. Wu WT \& Chen HL (2011) Konjac glucomannan and inulin systematically modulate antioxidant defense in rats fed a high-fat fiber-free diet. I Agri Food Chem 59, 9194-9200.

3. Kudelka MR, Ju T, Heimburg-Molinaro J, et al. (2015) Simple sugars to complex disease-mucin-type O-glycans in cancer. Adv Cancer Res 126, 53-135.

4. Kim YS \& Ho SB (2010) Intestinal goblet cells and mucins in health and disease: recent insights and progress. Curr Gastroenterol Rep 12, 319-330.

5. Rousseau K, Byrne C, Kim YS, et al. (2004) The complete genomic organization of the human MUC6 and MUC2 mucin genes. Genomics 83, 936-939.

6. Baldus SE \& Hanisch F-G (2000) Biochemistry and pathological importance of mucin-associated antigens in gastrointestinal neoplasia. Adv Cancer Res 79, 201-248.

7. Camilleri M (2019) Leaky gut: mechanisms, measurement and clinical implications in humans. Gut 68, 1516-1526.

8. Van Itallie CM \& Anderson JM (2014) Architecture of tight junctions and principles of molecular composition. Semin Cell Dev Biol 36, 157-165.

9. Seril DN, Liao J, Yang GY, et al. (2003) Oxidative stress and ulcerative colitis-associated carcinogenesis: studies in humans and animal models. Carcinogenesis 24, 353-362.

10. Babbs CF (1990) Free radicals and the etiology of colon cancer. Free Rad Biol Med 8, 191-200.

11. Seifert S \& Watzl B (2007) Inulin and oligofructose: review of experimental data on immune modulation. J Nutr 137, 2563s-2567s.

12. Doi K (1995) Effect of konjac fibre (glucomannan) on glucose and lipids. Eur J Clin Nutr 49, Suppl. 3, S190-S197.

13. Pool-Zobel B, van Loo J, Rowland I, et al. (2002) Experimental evidences on the potential of prebiotic fructans to reduce the risk of colon cancer. Br J Nutr 87, Suppl. 2, S273-S281.

14. Chen HL, Lin YM \& Wang YC (2010) Comparative effects of cellulose and soluble fibers (pectin, konjac glucomannan, inulin) on fecal water toxicity toward Caco- 2 cells, fecal bacteria enzymes, bile acid, and short-chain fatty acids. J Agri Food Chem 58, 10277-10281.

15. Chen H-L, Cheng H-C, Wu W-T, et al. (2008) Supplementation of konjac glucomannan into a low-fiber Chinese diet promoted bowel movement and improved colonic ecology in constipated adults-a placebo-controlled, diet-controlled trial. J Am Coll Nutr 27, 102-108.

16. Council of Agriculture, Executive Yuan (2018) Animal Protective Act of Taiwan. Taipei, Taiwan: Council of Agriculture. https://www.coa.gov.tw/ws.php?id=5698

17. National Research Council (US) Committee for the Update of the Guide for the Care and Use of Laboratory Animals (2011) Guide for the Care and Use of Laboratory Animals, 8th ed. Washington, DC: National Academies Press.

18. Reeves PG, Nielsen FH \& Fahey GC, Jr. (1993) AIN-93 purified diets for laboratory rodents: final report of the American Institute of Nutrition ad hoc writing committee on the reformulation of the AIN-76A rodent diet. J Nutr 123, 1939-1951.

19. Lison L (1954) Alcian blue $8 \mathrm{G}$ with chlorantine fast red $5 \mathrm{~B}$. A technic for selective staining of mucopolysaccharides. Stain Technol 29, 131-138.

20. Jansen GJ, Wildeboer-Veloo AC, Tonk RH, et al. (1999) Development and validation of an automated, microscopybased method for enumeration of groups of intestinal bacteria. J Microbiol Methods 37, 215-221. 
21. Nagahama M, Nagayasu K, Kobayashi K, et al. (2002) Binding component of Clostridium perfringens iota-toxin induces endocytosis in Vero cells. Infect Immun 70, 1909-1914.

22. Wang RF, Cao WW \& Cerniglia CE (1996) PCR detection and quantitation of predominant anaerobic bacteria in human and animal fecal samples. Appl Environ Microbiol 62, $1242-1247$.

23. Xue Z, Yu J, Zhao M, et al. (2017) Effects of synbiotics on intestinal mucosal barrier in rat model. Clin Nutr Exp 13, 12-21.

24. Pastorelli L, De Salvo C, Mercado JR, et al. (2013) Central role of the gut epithelial barrier in the pathogenesis of chronic intestinal inflammation: lessons learned from animal models and human genetics. Front Immunol 4, 280-280.

25. Emenaker NJ \& Basson MD (2001) Short chain fatty acids differentially modulate cellular phenotype and c-myc protein levels in primary human nonmalignant and malignant colonocytes. Digest Dis Sci 46, 96-105.

26. Hague A, Butt AJ \& Paraskeva C (1996) The role of butyrate in human colonic epithelial cells: an energy source or inducer of differentiation and apoptosis? Proc Nutr Soc 55, 937-943.

27. Wu W-T, Yang L-C \& Chen H-L (2014) Effects of konjac glucomannan, inulin and cellulose on acute colonic responses to genotoxic azoxymethane. Food Chem 155, 304-310.

28. Gill HS (2003) Probiotics to enhance anti-infective defences in the gastrointestinal tract. Best Pract Res Clin Gastroenterol 17, 755-773.

29. Mack DR, Michail S, Wei S, et al. (1999) Probiotics inhibit enteropathogenic $E$. coli adherence in vitro by inducing intestinal mucin gene expression. Am J Physiol 276, G941-G950.

30. Gaudier E, Rival M, Buisine MP, et al. (2009) Butyrate enemas upregulate Muc genes expression but decrease adherent mucus thickness in mice colon. Physiol Res 58, 111-119.

31. Wang HB, Wang PY, Wang X, et al. (2012) Butyrate enhances intestinal epithelial barrier function via up-regulation of tight junction protein Claudin-1 transcription. Dig Dis Sci 57, $3126-3135$.
32. Bordin M, D'Atri F, Guillemot L, et al. (2004) Histone deacetylase inhibitors up-regulate the expression of tight junction proteins. Mol Cancer Res 2, 692-701.

33. Gourbeyre P, Denery S \& Bodinier M (2011) Probiotics, prebiotics, and synbiotics: impact on the gut immune system and allergic reactions. J Leukoc Biol 89, 685-695.

34. Markowiak P \& Śliżewska K (2017) Effects of probiotics, prebiotics, and synbiotics on human health. Nutrients $9,1021$.

35. Kengatharan M, De Kimpe SJ \& Thiemermann C (1996) Analysis of the signal transduction in the induction of nitric oxide synthase by lipoteichoic acid in macrophages. $\mathrm{Br}$ J Pharmacol 117, 1163-1170.

36. Azad MAK, Sarker M \& Wan D (2018) Immunomodulatory effects of probiotics on cytokine profiles. Biomed Res Int 8063647

37. Moore KW, Malefyt RdW, Coffman RL, et al. (2001) Interleukin-10 and the interleukin-10 receptor. Ann Rev Immunol 19, 683-765.

38. Roller M, Pietro Femia A, Caderni G, et al. (2004) Intestinal immunity of rats with colon cancer is modulated by oligofructose-enriched inulin combined with Lactobacillus rhamnosus and Bifidobacterium lactis. Br J Nutr 92, 931-938.

39. Viladomiu M, Hontecillas R, Yuan L, et al. (2013) Nutritional protective mechanisms against gut inflammation. $J$ Nutr Biochem 24, 929-939.

40. Arenas-Padilla M, Duarte-Gutierrez JL \& Mata-Haro V (2018) Bifidobacterium animalis ssp. lactis Bb12 induces IL-10 through cell membrane-associated components via TLR2 in swine. J Appli Microbiol (epublication ahead of print 14 August 2018).

41. Yeh S-L, Wu T-C, Chan S-T, et al. (2014) Fructo-oligosaccharide attenuates the production of pro-inflammatory cytokines and the activation of $\mathrm{JNK} / \mathrm{Jun}$ pathway in the lungs of D-galactose-treated Balb/cJ mice. Eur J Nutr 53, 449-456.

42. Xie LM, Ge YY, Huang X, et al. (2015) Effects of fermentable dietary fiber supplementation on oxidative and inflammatory status in hemodialysis patients. Int J Clin Exp Med 8, 1363-1369. 